\title{
Rehabilitacija pasa oboljelih od akutnog idiopatskog poliradikuloneuritisa - prikaz slučajeva
}

\author{
A. Kraljević, F. Kajin, I. Kiš, N. Brkljača Bottegaro, B. Pirkić, T. Bureš i \\ Z. Vrbanac*
}

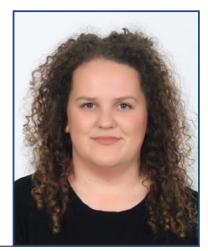

\section{Sažetak}

Akutni idiopatski poliradikuloneuritis (AIP) je stečena periferna neuropatija koja primarno zahvaća ventralne korijene spinalnih živaca i periferne živce. Bolest je vrlo slična Guillain-Barré sindromu u ljudi, a nema dobne, pasminske ni spolne predispozicije te ne postoji specifična terapija. Oporavak traje 2 - 6 mjeseci. Fizikalna terapija i njega pacijenata preporučuju se kao potporna terapija. Dva psa, križane pasmine $u$ dobi od šest i deset godina zaprimljeni su sa znacima akutne flakcidne tetrapareze/tetraplegije, u bočnom položaju bez mogućnosti da samostalno zauzmu sternalni položaj posljedično generaliziranoj zahvaćenosti nižih motoričkih neurona. Na svim ekstremitetima mišićni tonus je bio veoma slab. Dijagnoza AIP-a je bazirana na anamnezi, kliničkoj manifestaciji, neurološkom pregledu, slikovnoj dijagnostici i laboratorijskim testovima. Rehabilitacijski program je uključivao masažu ekstremiteta i

pasivne kretnje zglobova kao važan dio kućnog programa, elektroterapiju, hidroterapiju i proprioceptivne vježbe. Nakon dva tjedna fizikalne terapije psi su se mogli samostalno podignuti u sternalni položaj, a na stražnjim nogama pokazivali su i voljne pokrete. Potpomognuto stajanje i voljni pokreti svih ekstemiteta bili su prisutni na kraju trećeg tjedna $\mathrm{u}$ jednog psa i krajem petog tjedna $\mathrm{u}$ drugog psa. Nakon toga u proces rehabilitacije uključena je hidroterapija. Jedan pas je mogao samostalno hodati dvadeset petog dana od početka fizikalne terapije, dok je drugom psu bilo potrebno pedeset dana. Fizikalna terapija u kombinaciji s adekvatnim kućnim rehabilitacijskim programom može rezultirati skraćenim razdobljem oporavka za pacijente s AIP-om.

Ključne riječi: akutni idiopatski poliradikuloneuritis, pas, rehabilitacija

Anita KRALJEVIĆ, dr. med. vet., studentica poslijediplomskog specijalističkog studija, Filip KAJIN, dr. med. vet., asistent, dr. sc. Ivana KIŠ, dr. med. vet., izvanredna profesorica, dr. sc. Nika BRKLJAČA BOTTEGARO, dr. med. vet., docentica, dr. sc. Boris PIRKIĆ, dr. med. vet., redoviti profesor, Tomislav BUREŠ, dr. med. vet., asistent, dr. sc. Zoran VRBANAC*, dr. med. vet., DECVSMR, DACVSMR, docent, (dopisni autor, e-mail: zvrbanac@vef.hr), Veterinarski fakultet Sveučilišta u Zagrebu, Hrvatska 


\section{Uvod}

Akutni idiopatski poliradikuloneuritis (AIP) poznat i kao coonhound paraliza ili idiopatski poliradikuloneuritis, je bolest koja zahvaća akson i mijelinsku ovojnicu ventralnih korijena živaca, spinalne živce, kranijalne živce i periferne živce u pasa. Klinička manifestacija je vrlo slična Guillain-Barré (GBS) sindromu u ljudi (Olby, 2014., Dewey i Talarico 2016.). AIP predstavlja najčešću polineuropatiju koja se javlja u pasa (Cuddon, 2002., Olby, 2014., Ańor, 2014.). Termin „coonhound paraliza" odnosi se na pse koji su imali kontakt s rakunom u vidu ugriza i/ili ogrebotina prije nastanka kliničkih znakova poliradikuloneuritisa, dok se termin „idiopatski poliradikuloneuritis“ odnosi na pacijente koji imaju identičnu kliničku manifestaciju oboljenja, ali nisu bili u kontaktu s rakunima. Bolest je prvi put opisana 1954. godine $u$ pasa $u$ kojih je prošlo 7 do 10 dana od ugriza rakuna (Kingma i Catcott, 1954.).

Coonhound paraliza se javlja u pasa na prostoru Sjeverne, Centralne i dijelovima Južne Amerike, dok se idiopatski poliradikuloneuritis javlja diljem svijeta. Literaturni podatci o tome ima li utjecaja na fetus ukoliko je kuja gravidna ne postoje, a nema ni spolne, pasminske ni dobne predispozicije. Točna patogeneza ovog oboljenja nije poznata, ali se smatra da su uključeni imunosno-posredovani mehanizmi, koji zahvaćaju periferni mijelin, aksone ili i jedno i drugo, kao što je slučaj s GBS u ljudi (Cuddon 2002., Añor 2014., Dewey i Talarico 2016.).

Oboljenje se klinički karakterizira brzim nastankom pareze ili paralize nižih motoričkih neurona (NMN), koje se obično razvija unutar 24 do 72 sata, a počinje od stražnjeg dijela tijela te $u$ većini slučajeva dovodi do tetrapareze pa i tetraplegije. Pregledom kranijalnih živaca može se ustanoviti poremećaj VII. kranijalnog živaca, a ponekad i IX. i X. (Vaquero i Parent, 2016.). Česte su promjene u glasu, a ponekad dolazi i do nestanka glasa (disfonija, afonija). Prisutna je generalizirana hiporefleksija do arefleksija, uz izuzetak perinealnog refleksa koji je očuvan. Može se razviti teška neurogena atrofija mišića. Osjet duboke boli je očuvan. Psi su u mogućnosti kontrolirati uriniranje i defeciranje. U težim slučajevima može se razviti i respiratorna paraliza (Cuddon, 2002., Dewey i Talarico, 2016.).

Dijagnoza se postavlja na osnovu anamneze i kliničke manifestacije progresivne polineuropatije. Broj bolesti koje prouzroče akutne znakove NMN tetraplegije/ tetraparalize je ograničen i uvijek se mora posumnjati na poliradikuloneuritis. Druge bolesti koje diferencijalno dijagnostički dolaze u obzir su: botulizam i krpeljna paraliza (više se vezuju za područja Amerike i Australije) (Olby, 2014.). Premda vrlo rijetko, mijastenija gravis može imati vrlo sličnu kliničku manifestaciju. Definitivna se dijagnoza postavlja biopsijom živaca (Olby, 2014.), a i elektromiografija je pouzdana dijagnostička metoda koja se može koristiti. Najpouzdaniji pokazatelji da je riječ o AIP-u su elektromiografska (EMG) spontana aktivnost (posebno ukoliko se radi poslije četvrtog dana od pojave kliničke manifestacije), smanjenje amplitude sumacijskog mišićnog akcijskog potencijala, povećanje minimalne vrijednosti latentnog F-vala ili odsustvo F-valova, povećanje F omjera i smanjenje amplitude F-valova (Cuddon, 2002.). Zaključak istraživanja koje su proveli Stanciu i sur. (2014.) je taj da se AIP karakterizira povećanjem latentnog F-vala uz nespecifične EMG promjene. Analiza cerebrospinalne tekućine može pokazati povišenu razinu ukupnih proteina. Kompletna krvna slika, biokemijski parametri krvi i analiza urina su obično u fiziološkim granicama.

Ukoliko ne dođe do razvoja respiratorne paralize, prognoza je uglavnom povoljna. Većinom se psi s 
AIP-om $\mathrm{u}$ potpunosti oporave, iako $\mathrm{u}$ pasa $\mathrm{s}$ težim oblikom mogu perzistirati blagi neurološki deficiti (Cuddon, 2002.).

Do sada nije opisana specifična terapija za ovo oboljenje. Primjena kortikosteroida ne poboljšava kliničku sliku niti skraćuje razdoblje oporavka (Cuddon, 2002.). Istraživanje koje su proveli Hirschvogel i sur. (2012.) pokazalo je da su psi koji su bili terapirani IV imunoglobulinima za kraći vremenski period postali pokretni u usporedbi s psima iz kontrolne skupine koji nisu bili tretirani s IV imunoglobulinima. Većina se pacijenata s ovim oboljenjem spontano počinje oporavljati nakon trećeg tjedna, uz potpuni oporavak nakon dva do šest mjeseci (Stanciu i sur., 2014.). Intenzivna fizikalna terapija je vrlo učinkovita $u$ terapiji ovog oboljenja, ponajprije kako bi se smanjila neurogena mišićna atrofija i održavala pokretljivost zglobova. Cilj je ovog rada kroz prikaz dva slučaja opisati protokol fizikalno terapijske intervencije s ciljem skraćivanja vremena oporavka pasa oboljelih od AIP.

\section{Prikaz slučajeva}

\section{Slučaj 1}

Kujica križane pasmine, stara šest godina, nekastrirana, tjelesne mase 20,6 $\mathrm{kg}$ prije dolaska zaprimljena je u bočnom položaju (Slika 1). Prema anamnestičkim podatcima kuja je prije oko 12 sati počela naglo pokazivati znakove tetraplegije.

Vrijednosti trijasa bile su unutar fizioloških granica. $\mathrm{Na}$ palpaciju kralježnice kujica nije pokazivala znakove bolnosti, kao ni prilikom pasivnih kretnji vrata; nije mogla samostalno zauzeti sternalni položaj i bila je prisutna vrlo izrazita hipotonija mišića. Neurološkom pretragom (Tabela 1) utvrđeno je da su bili prisutni minimalni voljni pokreti ekstremiteta.

Naime, kako je kujica bila izrazito slaba i morala je biti podržavana za vrijeme testiranja propriocepcije, izgledala je kao da joj je propriocepcija odsutna na prednjim, a usporena na stražnjim ekstremitetima što indirektno odražava težinu zahvaćenosti nižih motoričkih neurona. Bila je uočena i arefleksija, uz izuzetak perinealnog refleksa koji je bio očuvan; na sva četiri ekstremiteta bio je prisutan osjet dubokog bola. Kujica je bila disfonična, a u tijeku pregleda nisu ustanovljeni deficiti drugih kranijalnih živaca.

Diferencijalne dijagnoze: akutni idiopatski poliradikuloneuritis, krpeljna paraliza, fulminantna mijastenija gravis, botulizam. Rendgenološkom pretragom uočena je spondiloza $u$ torakalnom i lumbalnom segmentu kralježnice, kao i suspektna hipovolemija. Nisu uočeni znaci svježih trauma ili diskopatija cijelom dužinom kralježnice.

Vrijednosti kompletne krvne slike i serumske biokemije pokazali su povećan udio nesegmentiranih neutrofila (3\%, fiziološki raspon $0-1 \%$ ), kao i povišenje kreatin-kinaze (427 U/L, fiziološki raspon do $160 \mathrm{U} / \mathrm{L})$.

Kuja je bila ukupno devet tjedana na fizikalnoj terapiji. Uz predloženi kućni

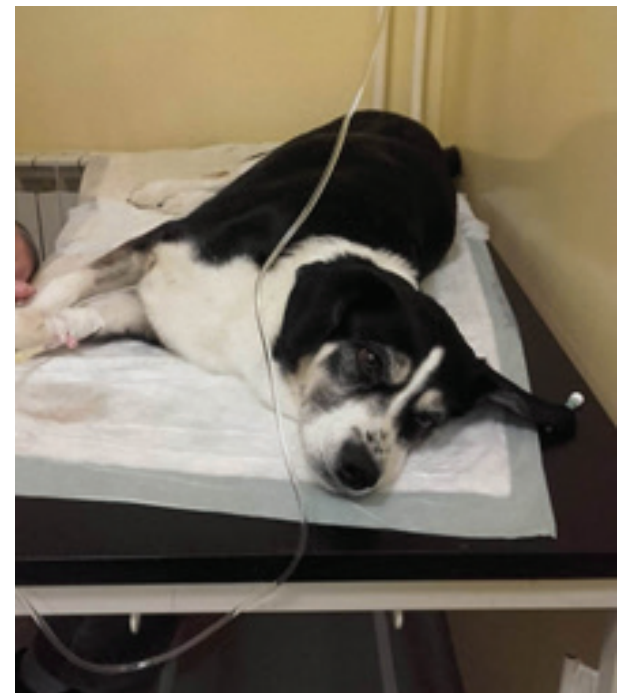

Slika 1. Kujica se po zaprimanju u ambulantu nalazila u bočnom položaju bez mogućnosti samostalnog zauzimanja sternalnog položaja 


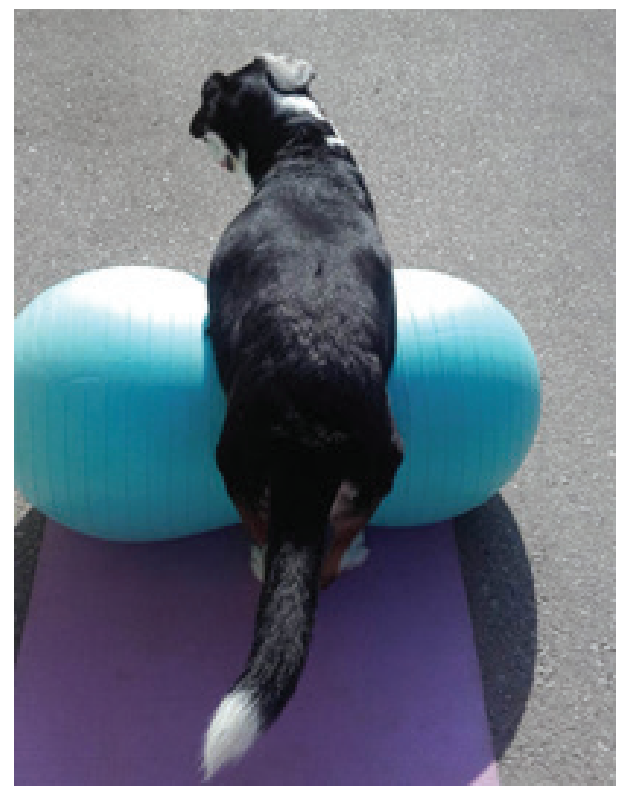

Slika 2. Kao dio kućnog programa vlasnicima je predloženo da izvode vježbe potpomognutog stajanja i ravnoteže s pacijentom, a jedna od njih se izvodila uz pomoć kikiriki pilates lopte

program koji se sastojao od pasivnih kretnji i masaže, u prvim tjednima primjenjivana je elektroterapija. Voljni pokreti stražnjih ekstremiteta uočeni su krajem drugog tjedna, a voljni pokreti svih ekstremiteta uz potpomognuto stajanje $\mathrm{u}$ petom tjednu (Slika 2). Pored navedenog, plan rehabilitacije uključivao je hidroterapiju i proprioceptivne vježbe. Pedesetog dana od početka fizikalne terapije pas je počeo samostalno hodati.

\section{Slučaj 2}

Kujica križane pasmine, kastrirana, stara deset godina, tjelesne mase $13 \mathrm{~kg}$ zaprimljena je sa znacima flakcidne tetrapareze. Vrijednosti trijasa bile su unutar fizioloških granica. Neurološkim pregledom ustanovljeni su nereproducibilni proprioceptivni deficiti, hiporefleksija miotaktičkih refleksa i refleksa povlačenja, hipotonija te atrofija muskulature na sva 4 ekstremiteta (Tabela 1). Vlasnici su prijavili promjenu glasa prilikom lajanja.

Diferencijalne dijagnoze: akutni idiopatski demijelinizirajući poliradikuloneuritis, fulminantna mijastenija gravis, krpeljna paraliza i botulizam. Rendgenološkom pretragom nije utvrđeno postojanje svježih znakova traume. U području vratne kralježnice, segment C6-C7, nalaze se početne sekundarne reakcije ventralno po trupovima kralježaka. Nativnom rendgenološkom pretragom nije bilo moguće isključiti cervikalnu diskopatiju. Pretragom likvora utvrđeno je da je broj stanica iznosio $1 / \mathrm{mm}^{3}$, a ukupni proteini $0,16 \mathrm{~g} / \mathrm{L}$.

Laboratorijskom pretragom krvi, vrijednosti kompletne krvne slike i serumske biokemije pokazali su blago povišenje hematokrita (57 \%, fiziološki raspon 37 - $55 \%)$, eozinofiliju $(2,05$ x 109/L, fiziološki raspon $0,10-1,25$ x $\left.10^{9} / \mathrm{L}\right)$, povišenje kretinin-kinaze (297 $\mathrm{U} / \mathrm{L}$, fiziološki raspon do $160 \mathrm{U} / \mathrm{L})$ i C-reaktivnog proteina (CRP) $(21,8 \mathrm{mg} / \mathrm{L}$, fiziološki raspon 0 do $10,7 \mathrm{mg} / \mathrm{L})$. 4DX test

Tabela 1. Usporedni prikaz rezultata neurološke pretrage za oba slučaja

\begin{tabular}{|l|l|l|}
\hline & Slučaj 1 & Slučaj 2 \\
\hline Kranijalni živci & Disfonija & Disfonija \\
\hline Spinalni refleksi & $\begin{array}{l}\text { Arefleksija } \\
\text { Očuvan perinealni refleks }\end{array}$ & $\begin{array}{l}\text { Hiporefleksija } \\
\text { Očuvan perinealni refleks }\end{array}$ \\
\hline Osjet dubokog bola & Prisutan & Prisutan \\
\hline Refleks povlačenja & Hiporefleksija & Hiporefleksija \\
\hline Tonus mišića & Hipotonija & Hipotonija \\
\hline Atrofija mišića & Bez znakova atrofije & Generalizirana \\
\hline
\end{tabular}


(Anaplasma phagocytophilum/Anaplasma platys, Borrelia burdorferi, Ehrlichia canis, Dirofilaria immitis; Idexx) je bio negativan. Kujici je apliciran pripravak na bazi afoxolanera i milbemycin oximea (Nexgard $^{\circledR}$, Merial, Francuska) zbog moguće krpeljne paralize.

Nakon provedenih dijagnostičkih postupaka pas je započeo fizikalnu terapiju koja je ukupno trajala osam tjedana. Nakon drugog tjedna bili su prisutni voljni pokreti na stražnjim ekstremitetima, a nakon trećeg tjedna voljni pokreti su bili prisutni na svim ekstremitetima i pas je mogao potpomognuto hodati (Slika 3). Nakon toga $u$ rehabilitacijski proces uključena je i hidroterapija (Slika 4). Trajanja hidroterapije kao i brzina pokretne trake

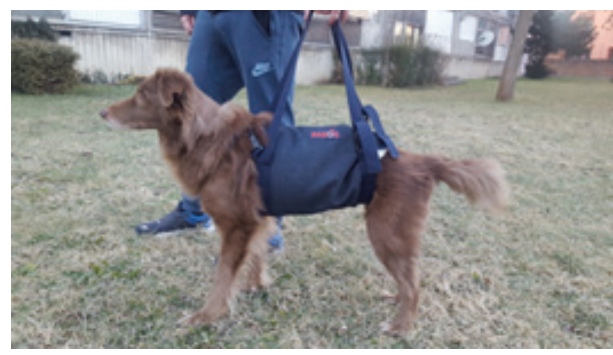

Slika 3. Potpomognuto kretanje psa je počelo krajem trećeg tjedna od početka fizikalne terapije. Vlasnici su kao potporu prilikom hodanja koristili nosiljku

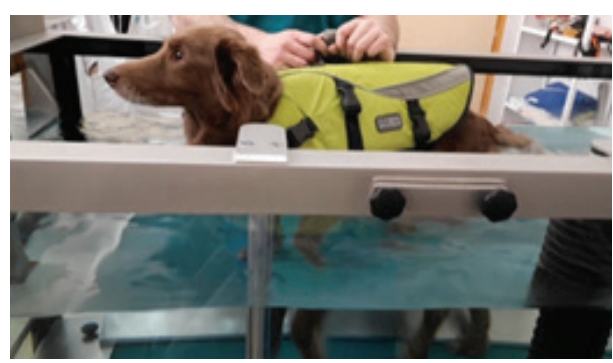

Slika 4. Hidroterapija: Nakon što je pas napravio samostalno nekoliko koraka u terapiju je uključeno hodanje u bazenu s pokretnom trakom. Zbog sigurnosti pacijenta i potpore vratnog i grudnog dijela kralježnice psu je stavljen sigurnosni pojas

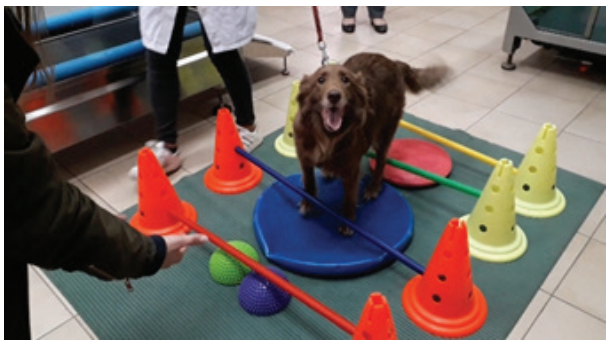

Slika 5. Proprioceptivne vježbe: Prelazak preko prepreka uz promjenu konfiguracije podloge, primjenjivao se u okviru proprioceptivnih vježbi u svrhu poboljšanja koordinacije pokreta

povećala se s oporavkom pacijenta. Pored toga radile su se terapijske vježbe koje su uključivale balans ploču i hodanje preko prepreka (Slika 5). Dvadeset petog dana od početka fizikalne terapije pas je samostalno napravio nekoliko koraka. Fizikalna terapija je nastavljena u smjeru jačanja mišića i poboljšavanja koordinacije pokreta.

\section{Rasprava}

Akutni idiopatski poliradikuloneuritis (coonhound paraliza, akutni poliradikuloneuritis) smatra se jednom od najčešćih polineuropatija koje se susreće $u$ pasa, stoga ukoliko se u psa pojavi akutna NMN tetrapareza/tetraparaliza, zbog takve kliničke manifestacije mora se posumnjati na AIP. Druge bolesti koje je potrebno diferencijalno dijagnostički isključiti su: mijastenija gravis, botulizam i krpeljna paraliza. S obzirom da se botulizam i krpeljna paraliza uglavnom pojavljuju na području Amerike i Australije (Olby, 2014.) manje će biti vjerojatno da se radi o tim bolestima, a iz anamneze možemo dobiti informacije je li pas bio izložen botulinus toksinu, je li se primjenjivala terapija protiv ektoparazita i koja te jesu li su unatoč tome uočeni krpelji na psu. Dijagnostika uključuje analizu cerebrospinalnog likvora, elektrodijagnostiku te biopsiju živaca kao definitivnu dijagnozu (Olby, 2014.). 
Pacijentima $u$ našem istraživanju provedena je dijagnostika koja se sastojala od anamneze, općeg kliničkog i neurološkog pregleda te provedenih dodatnih laboratorijskih pretraga te je dijagnoza postavljena na temelju isključivanja drugih uzroka generalizirane slabosti na sličan način kako je provedeno u studiji koju su proveli Martinez-Anton i sur. (2018.). Iz tehničkih razloga elektrodijagnostika i biopsija nisu učinjene, a analizom cerebrospinalnog likvora u slučaju 1 nije utvrđeno povišenje ukupnih proteina, što se ne može smatrati isključnim čimbenikom obzirom da se radilo o punkciji na cisterna magna dok se kod AIP povišenje proteina u likvoru očekuje kod lumbalne punkcije (Añor, 2014.).

Zanimljivo je da su u naše istraživanje bile uključene dvije kujice križane pasmine dok $u$ istraživanju iz Australije (Martinez-Anton i sur., 2018.) uopće nije bilo križanaca, a u istraživanju iz Velike Britanije (Laws i sur., 2017.) utvrđen je znatno viši rizik oboljevanja za pasmine Parson Jack Russel i West Highland White Terrier. Rehabilitacija pacijenata s oboljenjima živčanog sustava može biti vrlo izazovna, posebno ukoliko se radi o bolestima koje se odlikuju tetraparezom ekstremiteta, kao što je slučaj kod AIP-a. Cilj rehabilitacijskog programa pacijenata $s$ oboljenjima donjih motoričkih neurona je obnova i održavanje opsega kretnji zglobova, jačanje mišićne snage te obnavljanje Živčanomišićne funkcije (Thomas i sur., 2014.).

$S$ obzirom da spomenuti pacijenti uglavnom ne mogu samostalno zauzeti sternalni položaj, podložniji su komplikacijama od strane dišnog sustava. Zbog toga je vrlo važno da im bude omogućena odgovarajuća njega, osobito na samom početku bolesti. Neophodno je da se svaka četiri sata okreću kako bi spriječili nastanak atelektaza ili nakupljanja plućnog sekreta, što je uključivao i naš protokol rehabilitacije. Uz mekani ležaj i podlogu na kojoj borave, na ovaj način preveniramo i nastajanje dekubitalnih rana (Campbell i Huntingford, 2016.).

Kućni program u oba prikazana slučaja uz opisanu njegu i okretanje, uključivao je masažu, pasivne kretnje zglobova (engl. Passive Range of Motion; PROM) i vježbe ravnoteže koje su se izvodile dva do četiri puta dnevno. Primarna korist PROM-a ogleda se $u$ sprječavanju ukočenosti ili stvaranja fibroze zgloba. Druge koristi uključuju preveniranje nastanka atrofije hrskavice, nadopunjavanje sinovijalne tekućine koja predstavlja primarni izvor hranjivih sastojaka za hrskavicu, poboljšava cirkulaciju tretiranog područja i stimulira senzorne i proprioceptivne puteve uz sinovijalnu membranu i periartikularne strukture (Sims i sur., 2015.).

$S$ obzirom na to da psi iz gore opisanih slučajeva nisu bili u mogućnosti samostalno nositi svoje tijelo jer su ekstremiteti bili flakcidni, primjenjivana je maksimalna asistencija. Maksimalna asistencija se može definirati kao potpora od $75 \%$ do $100 \%$ tjelesne mase pacijenta da bi se održao u stojećem stavu (Millis i sur., 2014.a,b). Kada se pas postavi u stojeći stav veoma je bitno da svi ekstemiteti budu u fiziološkom položaju s pravilno pozicioniranim šapama. Kako pacijenti napreduju, potpora koju trebaju postaje sve manja. Za potpomognuto stajanje kad pacijenti ne mogu samostalno stajati možemo i trup pacijenta poduprijeti pilates loptom odgovarajuće veličine, što je $u$ naših pacijenata i primjenjivano.

Primjenom elektroterapije $u$ pacijenata $\mathrm{s}$ oboljenjem perifernog živčanog sustava može se odgoditi početak neurogene mišićne atrofije (Kern i sur., 2005.). Elektroterapija u ovom slučaju primjenjivana je $u$ obliku elektroakupunkture. Hidroterapija se izvodila $\mathrm{u}$ bazenu $\mathrm{s}$ pokretnom trakom 
pri čemu je razina vode bila $\mathrm{u}$ visini velikog trohantera bedrene kosti, što je značilo da je tjelesna masa psa uronjenog $\mathrm{u}$ vodu umanjena za približno $62 \%$ (Levine i sur., 2010.). Tijekom kranijalne faze koraka otpor koji pruža voda dovodi do povećavanja aktivnosti mišića. Temperatura vode iznosila je $28{ }^{\circ} \mathrm{C}$, što je vrlo korisno $u$ neuroloških pacijenata jer dovodi do opuštanja mišića. Toplija voda povećava cirkulaciju, provodljivost živaca, poboljšava koordinaciju pokreta i povećava elastičnost mekih tkiva (Levine i sur., 2014.). Plivanje se također može primijeniti kao oblik terapije, no hodanje $\mathrm{u}$ bazenu s pokretnom trakom $\mathrm{u}$ usporedbi $\mathrm{s}$ plivanjem dovodi do ranije aktivne kretnje zglobova, posebno fleksije, i jača mišiće (Levine i sur., 2014.). Vremensko trajanje hidroterapije kao i brzina pokretne trake prilagođavaju se individualno pacijentu. Poželjno je tijekom hidroterapije osigurati potporu vratnog i grudnog dijela psa, što je i učinjeno postavljanjem sigurnosnog pojasa. Na ovaj način umanjujemo mogućnost nastajanja ozljede.

U okviru proprioceptivnih vježbi izvodile su se vježbe na balans ploči te prelazak preko prepreka uz postavljene proprioceptivne diskove kako bi se promijenila konfiguracija podloge po kojoj su hodali. Prilikom izvođenja vježbe na balans ploči, svi ekstremiteti pacijenta su se nalazili na platformi, uz lagano pridržavanje psa, pokreti balans ploče su bili sporiji i ritmični na početku, da bi se kako pacijent napreduje ubrzavali i postali izazovniji. Koristi od ove vježbe su poboljšavanje ravnoteže, propriocepcije te jačanje mišića. Prelazak preko prepreka primjenjuje se za poticanje većeg aktivnog opsega kretnji zglobova i za produljenje koraka na svim ekstremitetima. U neuroloških pacijenata može biti od velike koristi jer dovodi do poboljšanja propriocepcije, ravnoteže i koordinacije. Na samom početku visina prepreka treba biti $u$ razini karpusa psa, vremenom, kako pas napreduje, razina na kojoj se nalaze prepreke može se povećavati. Hodanje preko prepreka dovodi do znatnog povećanja fleksije lakta, karpalnog, koljenog i tarzalnog zgloba te ekstenzije karpalnog i koljenog zgloba $\mathrm{u}$ usporedbi $\mathrm{s}$ neometanim hodanjem (Holler i sur., 2010.).

Pregledom literature do sada nije opisana uspješna specifična terapija AIP u pasa, već isključivo fizikalna terapija uz potpornu njegu. Istraživanje provedeno na temelju učinkovite primjene imunoglobulina u ljudi s GBS pokazalo je da su psi oboljeli od AIP koji su dobivali IV imunoglobuline počeli hodati bez pomoći u prosjeku za 27,5 dana (15 - 127 dana) od početka kliničke manifestacije, a psi iz kontrolne skupine koji su podvrgnuti fizikalnoj terapiji u prosjeku za 75,5 dana (5 - 220 dana) (Hirschvogel i sur., 2012.). Preliminarno istraživanje koju su proveli Asnal i sur. (2019.) pokazalo je da srednje vrijeme od početka fizikalne terapije do trenutka kada su psi ponovno postali pokretni iznosi 21,6 dana. U našem slučaju, pacijent koji je zaprimljen sa znacima tetrapareze je postao pokretan dvadeset petog dana od početka fizikalne terapije, dok je drugom, koji je bio tetraplegičan, po primitku bilo potrebno pedeset dana. Razlika u trajanju oporavka mogla bi se objasniti činjenicom da je obično u težih kliničkih znakova oporavak duži te može potrajati čak i 4 - 6 mjeseci (Cuddon, 2002.).

\section{Zaključak}

Plan oporavka pasa s dijagnozom AIP uglavnom ne uključuje medikamentoznu terapiju, izuzetak su slučajevi kada se razviju teške komplikacije drugih organskih sustava. Intenzivna fizikalna terapija uz adekvatnu kućnu njegu i vježbanje može pridonijeti skraćenju razdoblja oporavka u pasa $\mathrm{s}$ ovim oboljenjem. 


\section{Literatura}

1. AÑOR, S. (2014): Acute Lower Motor Neuron Tetraparesis. Vet. Clin. North Am. Small Anim. Pract. 44, 1201-1222.

2. ASNAL, L., V. MUSELLA, S. VALENTINI and G. SPINELLA (2019): Non-ambulatory tetraparesis secondary to acute polyradiculoneuritis in five dogs: a preliminary study on correlation between physiotherapy and recovery time. $6^{\text {th }}$ VEPRA- $1^{\text {st }}$ ECVSMR Conference Proceedings. (Ghent, 19-21 September 2019), 127.

3. CAMPBELL, M. T. and J. L. HUNTINGFORD (2016): Nursing Care and Rehabilitation Therapy for Patients with Neurologic Disease. In: C. W. Dewey, R. C. Da Costa Practical Guide to Canine and Feline Neurology, third edition. John Wiley and Sons Ltd, Hoboken (US) 559-584.

4. CUDDON, P. A. (2002): Acquired Canine Peripheral Neuropathies. Vet. Clin. North Am. Small Anim. Pract. 32, 207-249.

5. DEWEY, C. W. and L. R. TALARICO (2016): Disorders of the Peripheral Nervous System. In: C. W. Dewey, R. C. Da Costa. Practical Guide to Canine and Feline Neurology. John Wiley and Sons Ltd, Hoboken (US), 445-479.

6. HIRSCHVOGEL, K., K. JURINA, T. A. STEINBERG, L. A. MATIASEK, E. BELTRAN and A. FISCHER (2012): Clinical Course of Acute Canine Polyradiculoneuritis Following Treatment with Human IV Immunoglobulin. J. Am. Anim. Hosp. Assoc. 48, 299-309.

7. HOLLER, P. J., V. BRAZDA, B. DAL-BIANCO, E. LEWY, M. C. MUELLER, C. PEHAM and B. A. BOCKSTAHLER (2010): Kinematic motion analysis of the joints of the forelimbs and hind limbs of dogs during walking exercise regimens. Am. J. Vet. Res. 71, 734-740.

8. KERN, H., S. SALOMONS, W. MAYR, K. ROSSINI and U. CARRARO (2005): Recovery of long-term denervated human muscles induced by electrical stimulation. Muscle Nerve 31, 98-101.

9. KINGMA, F. J. and E. J. CATCOTT (1954): A paralytic syndrome in coonhounds. N. Am. Vet. 35, 115-117.

10. LAWS, E. J., T. R. HARCOURT-BROWN, N. GRANGER and J. H. ROSE (2017): An exploratory study into factors influencing development of acute canine polyradiculoneuritis in the UK. J. Small Anim. Pract. 58, 437-443.

11. MARTINEZ-ANTON, L., M. MARENDA, S. M. FIRESTONE, R. N. BUSHELL, G. CHILD,
A. I. HAMILTON, S. N. LONG and M. A. R. LE CHEVOIR (2018): Investigation of the role of Campylobacter infection in suspected acute polyradiculoneuritis in dogs. J. Vet. Intern. Med. 32, 352-360.

12. LEVINE, D., D. J. MARCELLIN-LITTLE, D. L. MILLIS, V. TRAGAUER and J. A. OSBORNE (2010): Effects of partial immersion in water on vertical ground reaction forces and weight distribution in dogs. Am. J. Vet. Res. 71, 1413-1416.

13. LEVINE, D., D. L. MILLIS, J. FLOCKER and L. MACGUIRE (2014): Aquatic Therapy. In: D. L. Millis, D. Levine. Canine Rehabilitation and Physical Therapy, Elsevier Health Sciences, London, pp. 526-542.

14. MILLIS, D. L., M. DRUM and D. LEVINE (2014a): Therapeutic Exercises: Early Limb Use Exercises. In: D. L. Millis, D. Levine. Canine Rehabilitation and Physical Therapy, second edition, Elsevier Health Sciences, London, pp. 495-505.

15. MILLIS, D. L., M. DRUM and D. LEVINE (2014b): Therapeutic Exercises: Joint Motion, Strengthening, Endurance, and Speed Exercises. In: D. L. Millis, D. Levine. Canine Rehabilitation and Physical Therapy, Elsevier Health Sciences, London, pp. 506-525.

16. OLBY, N. (2014): Tetraparesis. In: S. Platt, N. Olby, BSAVA Manual of Canine and Feline Neurology, fourth edition, British Small Animal Veterinary Association, Quedgeley, Gloucs (UK), pp. 271-296.

17. SIMS, C., R. WALDRON and D. J. MARCELLINLITTLE (2015): Rehabilitation and Physical Therapy for the Neurologic Veterinary Patient. Vet. Clin. Small Anim. 45, 123-143.

18. STANCIU, G. D., M. MUSTEATA, M. ARMASU, P. M. SAFTENCU and G. SOLCAN (2014): Electrophysiological Aspects in Idiopathic Acute Canine Polyradiculoneuritis. Bull. UASVM Vet. Med. 71, 292-297.

19. THOMAS, W. B., N. OLBY and L. SHARON (2014): Neurologic Condition and Physical Rehabilitation of the Neurologic Patient. In: D. L. Millis, D. Levine. Canine Rehabilitation and Physical Therapy, second edition, Elsevier Health Sciences, London, 609-627.

20. VAQUERO, P. M. and J. M. PARENT (2016): Coonhound Paralysis (Acute Polyradiculoneuritis) In: L. P. Tilley, F. W. K. Smith Jr. Blackwell's FiveMinute Veterinary Consult: Canine and Feline, sixth edition, John Wiley \& Sons, Inc, New York (US), 318-319. 


\section{Rehabilitation of dogs from Acute Idiopathic Polyradiculoneuritis - a case report}

Anita KRALJEVIĆ, DVM, Student of Postgraduate Specialistic Study, Filip KAJIN, DVM, Assistant, Ivana KIŠ, DVM, PhD, Associate Professor, Nika BRKLJAČA BOTTEGARO, DVM, PhD, Assistant Professor, Boris PIRKIĆ, DVM, PhD, Full Professor, Tomislav BUREŠ, DVM, Assistant, Zoran VRBANAC, DVM, PhD, DECVSMR, DACVSMR, Assistant Professor, Faculty of Veterinary Medicine University of Zagreb, Croatia

Acute idiopathic polyradiculoneuritis (AIP) is an acquired peripheral neuropathy that primarily affects the ventral spinal nerve roots and peripheral nerves. The disease is very similar to Guillan Barré syndrome in humans. There is no age, breed, or sex predilection associated with the development of AIP. No proven specific treatment exists. Recovery occurs within 2 - 6 months. Physical therapy and nursing care are recommended as supportive treatment. Two female mix breed dogs, aged 6 and 10 years, were admitted to the physical therapy unit with signs of acute flaccid non-ambulatory tetraparesis/tetraplegia in lateral recumbency, unable to assume the sternal position unassisted as a consequence of generalised lower motor neuron signs. Reduced to absent muscle tone was present in all limbs. A tentative diagnosis of AIP was made based on history, clinical presentation, neurologic examination, diagnostic imaging and routine laboratory tests. The rehabilitation programme included massage, joint passive range of motion (PROM) as an important part of the home programme, electrotherapy, hydrotherapy and proprioceptive exercises. After two weeks, dogs were able to maintain a sternal position without support, and showed voluntary movement of the hind limbs. Assistive standing and voluntary movements of all limbs were present by the end of third week in one patient, and fifth week in the other. At that point, underwater treadmill sessions and active exercises were introduced. Dogs were ambulating without assistance after 25 days in one patient and after 50 days in other. Physical therapy combined with a proper home rehabilitation programme can result in a positive functional outcome in a shorter period of time in dogs with AIP.

Key words: Idiopathic polyradiculoneuritis; canine; rehabilitation 